\title{
Do parents with an atopic family history adopt a 'prudent' lifestyle for their infant? (KOALA Study)
}

Citation for published version (APA):

Kummeling, I., Thijs, C., Stelma, F. F., Huber, M., van den Brandt, P. A., \& Dagnelie, P. C. (2006). Do parents with an atopic family history adopt a 'prudent' lifestyle for their infant? (KOALA Study). Clinical and Experimental Allergy, 36(4), 489-494. https://doi.org/10.1111/j.1365-2222.2006.02473.x

Document status and date:

Published: 01/01/2006

DOI:

10.1111/j.1365-2222.2006.02473.x

Document Version:

Publisher's PDF, also known as Version of record

\section{Please check the document version of this publication:}

- A submitted manuscript is the version of the article upon submission and before peer-review. There can be important differences between the submitted version and the official published version of record.

People interested in the research are advised to contact the author for the final version of the publication, or visit the DOI to the publisher's website.

- The final author version and the galley proof are versions of the publication after peer review.

- The final published version features the final layout of the paper including the volume, issue and page numbers.

Link to publication

\footnotetext{
General rights rights.

- You may freely distribute the URL identifying the publication in the public portal. please follow below link for the End User Agreement:

www.umlib.nl/taverne-license

Take down policy

If you believe that this document breaches copyright please contact us at:

repository@maastrichtuniversity.nl

providing details and we will investigate your claim.
}

Copyright and moral rights for the publications made accessible in the public portal are retained by the authors and/or other copyright owners and it is a condition of accessing publications that users recognise and abide by the legal requirements associated with these

- Users may download and print one copy of any publication from the public portal for the purpose of private study or research.

- You may not further distribute the material or use it for any profit-making activity or commercial gain

If the publication is distributed under the terms of Article $25 \mathrm{fa}$ of the Dutch Copyright Act, indicated by the "Taverne" license above, 


\title{
Do parents with an atopic family history adopt a 'prudent' lifestyle for their infant? (KOALA Study)
}

\author{
I. Kummeling* , C. Thijs ${ }^{* \dagger}$, F. Stelma ${ }^{\ddagger}$, M. Huber ${ }^{\S}$, P. A. van den Brandt* and P. C Dagnelie ${ }^{\dagger}$ \\ * Department of Epidemiology, Care and Public Health Research Institute (Caphri), Maastricht University, Maastricht, The Netherlands, ${ }^{\dagger}$ Department of Epidemiology, \\ Nutrition and Toxicology Research Institute Maastricht (NUTRIM), Maastricht University, Maastricht, The Netherlands, ${ }^{\ddagger}$ Department of Medical Microbiology, \\ University Hospital of Maastricht, Maastricht, The Netherlands and ${ }^{\S}$ Louis Bolk Institute, Driebergen, The Netherlands
}

\section{Clinical and Experimental Allergy}

Correspondence:

Ischa Kummeling, Department of Epidemiology, Maastricht University, PO Box 616, 6200 MD, Maastricht, The Netherlands.

E-mail: Ischa.Kummeling@epid. unimaas.nl

\begin{abstract}
Summary
Background Atopic parents may adopt lifestyle characteristics that allegedly protect against atopic disease. If this is true, infants from atopic parents will be characterized by low-risk behaviour. Consequently, aetiologic studies on lifestyle factors and allergic disease in childhood may be biased by confounding by indication.

Objective We explored whether the prevalence of 'prudent' lifestyle characteristics differs between atopic and non-atopic families.

Methods Information about a family history of atopic manifestations and lifestyle characteristics was collected by repeated questionnaires in the Dutch KOALA Birth Cohort Study in 2469 infants from families with divergent lifestyle practices (conventional vs. alternative).

Results In conventional lifestyle families, infants were less often exposed to environmental tobacco smoke when parents were atopic than when they were non-atopic (10.0\% vs. 14.7\%, $P=0.001$ ). In alternative lifestyle families, exposure to smoking was very rare in both groups $(1.7 \%$ vs. $2.6 \%)$. Pets were less often present in families with than without parental atopy (38.8\% vs. 51.1\%, $P=0.008$ for conventional lifestyle families; $43.0 \%$ vs. $48.4 \%, P=0.014$ for alternative lifestyle families). Infants with atopic siblings had less often been vaccinated according to the standard scheme than infants with non-atopic siblings in conventional lifestyle families $(76.6 \%$ vs. $85.5 \%, P<0.001)$. In alternative lifestyle families, the difference was in the same direction but not statistically significant ( $30.1 \%$ vs. $40.5 \%, P=0.143$ ). Antibiotic use, breastfeeding and consumption of organic foods were unrelated to a family history of atopic manifestations.

Conclusion Some 'prudent' lifestyle characteristics differed between atopic and non-atopic families, depending on whether atopic manifestations were present in parents or older siblings. This has important consequences for the validity in epidemiological studies on the aetiology of allergy in children. Confounding by indication because of a family history of atopic manifestations can best be controlled for by considering atopy in parents and siblings as separate confounders.
\end{abstract}

Keywords confounding, infant, family history of atopy, lifestyle, parents

Submitted 5 September 2005; revised 18 November 2005; accepted 20 January 2006

\section{Introduction}

These days in modern societies uncountable internet websites, magazines and newspaper articles are devoted to childhood allergy. This public concern tags along with scientific evidence that the prevalence of atopic diseases such as asthma, atopic eczema and allergic rhino- conjunctivitis has increased over the past decades $[1,2]$. Currently one-third of the children in westernized societies show atopic symptoms [3].

A positive family history for atopy has proved to be an important risk factor for the development of atopic disease in offspring [4]. Several findings have led to the notion that certain lifestyle practices may also be associated with 
atopy. First, studies performed in different geographical areas indicated that a western lifestyle predisposed to atopic disease [3, 5, 6]. Moreover, important regional differences in disease prevalence were revealed in genetically similar populations, indicating that rapid changes in genetic background cannot explain the epidemic [7]. A Swedish study suggested that an anthroposophic lifestyle might lessen the risk of atopy in childhood [8]; growing up on a farm has also been reported to be protective [9-11].

In order to determine which specific lifestyle factors are important, research on the aetiology of atopy has focused on changes in lifestyle over the past decades. The introduction of vaccinations and antibiotics, smaller family sizes and better hygiene are associated with atopy. The common denominator to these factors is decreased microbial stimulation $[8,12-17]$. Also, altered patterns of food consumption $[18,19]$ and increased exposure and sensitization to indoor allergens [20-23] are considered important cofactors for the development of atopic disease in westernized societies.

As information on childhood allergy on the Internet or in magazines is easily accessible, modern parents have become more aware of the important role that their lifestyle plays in relation to atopy. Consequently, they may seek to adapt their behaviour in an attempt to prevent allergy in their child, in particular in families with a history of atopic manifestations. This causes differences in exposure to important risk or protective factors in early life between children of atopic and non-atopic families [24]. Consequently, the validity of epidemiological research concerning the role of lifestyle factors in relation to atopic disease is affected: if atopic families adopt a 'prudent' lifestyle, i.e. a lifestyle which allegedly protects against atopic disease, the effect of lifestyle on the development of atopy will be confounded by family history of atopy (confounding by indication) (Fig. 1). A protective lifestyle factor may then appear as a risk factor, because the exposed subjects are at the highest risk.

The aim of this publication was to explore whether parents with a family history of atopic manifestations adopt a 'prudent' lifestyle relative to parents of non-atopic families, using families with divergent lifestyle practices selected from the Dutch KOALA Birth Cohort Study. We specifically addressed the issue of differential effects of atopy in parents vs. siblings on lifestyle practices, which

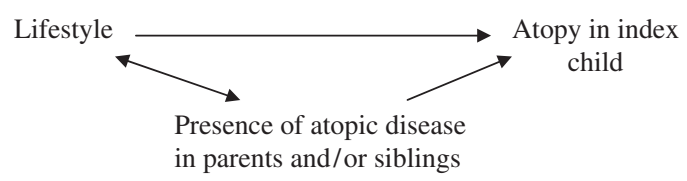

Fig. 1. Schematic presentation of confounding by indication by family history of the observed association between the exposure to a certain lifestyle factor and the presence of atopy. to our knowledge has not been reported in allergy studies to date.

\section{Subjects and methods}

\section{Study population}

A detailed description of the design of our cohort was published previously [25]. In summary, the Dutch KOALA Birth Cohort Study started in October 2000. Participants were recruited from two sources. First, pregnant women were recruited from an ongoing prospective cohort study on pregnancy-related pelvic girdle pain (PPGP study) [26]. Participants of the PPGP study were recruited via midwife clinics at 14-16 weeks of gestation. At 34 weeks of gestation PPGP subjects were asked to participate in the KOALA study ('conventional subcohort'). Second, to increase the number of participants with lifestyle choices that have a low prevalence in the general population, pregnant women with the so-called 'alternative' lifestyles were recruited through several specific recruitment channels, i.e. anthroposophic doctors and midwifes, anthroposophic under-five clinics, Steiner Schools, posters and flyers in organic food shops and magazines for special interest groups (e.g. homeopathy, anthroposophy, antivaccine) ('alternative subcohort'). These women were also enrolled at 14-18 weeks of gestation. A total of 2834 participants were included in the KOALA study, 2343 through the PPGP study and 491 through the specific recruitment channels. All participants signed informed consent and completed the first (pregnancy) questionnaire at 34 week of gestation. Parents in both subcohorts were sent detailed questionnaires when the infants were 3 and 7 months of age. Age 7 months was selected to have complete information on the first 6 months of life of infants.

In the present publication we report on lifestyle characteristics in the first 6 months of life. Data on a family history of atopic manifestations and sibship size were collected by questionnaires with closed answer options at 34 weeks of gestation. Questionnaires at 34 weeks of gestation, 3 and 7 months postpartum were used to collect information about lifestyle characteristics.

Out of 2343 conventional and 491 alternative subcohort participants, 2003 (85\%) and 466 (95\%), respectively, completed the 'family history of atopic manifestations' questionnaire as well as the 3 and 7 months postpartum questionnaires. Ethical approval was obtained from the medical ethics committee of the Maastricht University/ University Hospital of Maastricht.

\section{Definitions}

Positive family history of atopic manifestations included self-reported doctor's diagnosed asthma, pet or house dust 
mite (HDM) allergy, hayfever and/or eczema for parents (none vs. one or both) and older siblings (none vs. one or more), separately. Food allergy was included in the definition of atopy for older siblings only.

At 7 months postpartum, we asked parents whether their child had been vaccinated according to the standard scheme, an 'alternative vaccination scheme' or not at all. In the Netherlands during the time of the study, infants in their first 6 months were standard vaccinated against diphtheria, tetanus, pertussis (with whole cell pertussis vaccine), poliomyelitis and Haemophilus influenzae type $B$ vaccine (Hib) at 2, 3 and 4 months of age. An 'alternative vaccination scheme' was defined as delayed vaccinations or alternative vaccine composition (for example, omitting the Pertussis component from the Diphtheria-PertussisTetanus-Polio vaccine).

We asked parents if their child had ever used antibiotics (yes/no), whether the child had been exposed to environmental tobacco smoke (ETS) for more than one hour per week (yes/no) and if they had pets in the house at any time (yes/no). We defined 'exclusive breastfeeding' as breastfeeding without any artificial and/or supplemental feeding in the first 4 months of life. Consumption of organic bananas (fresh) (yes/no) and organic fruit (jar) (yes/no) were used as indicator variables for choice for organic foods when starting supplemental feeding, because these were the foods most used in the first 6 months.

\section{Statistical analyses}

We evaluated associations between lifestyle choices and the presence of a family history of atopic manifestations by Pearson's $\chi^{2}$ test. The evaluation of associations between lifestyle choices and sibling history of atopic manifestations was restricted to families with one or more older siblings. Determination of whether choice for organic fruit (fresh and jar) is related to family history of atopic diseases was restricted to infants who had actually consumed these foods. P-values below 0.05 indicated statistical significance.

\section{Results}

About half of the families in both subcohorts had a parental history of atopic manifestations (Table 1). About $34.7 \%$ of index children in the alternative and $46.7 \%$ in the conventional subcohort had no older siblings. The percentage of families with a positive sibling's history of atopic manifestations was around $14.7 \%$ in the alternative and $20.0 \%$ in the conventional subcohort. The percentage of infants vaccinated according to the standard scheme was lower in the alternative lifestyle families than in conventional families (42.6\% vs. $80.9 \%$ ), and the same was true for antibiotic use (13.3\% vs. 22.9\%). Exposure of infants to environmental tobacco smoke (ETS) was rare in
Table 1. Characteristics of a conventional $(N=2003)$ and alternative subcohort $(N=466)$ in the KOALA Birth Cohort Study over the first 6 months after birth

\begin{tabular}{|c|c|c|c|c|}
\hline & \multicolumn{2}{|c|}{$\begin{array}{l}\text { Conventional } \\
\text { subcohort }\end{array}$} & \multicolumn{2}{|c|}{$\begin{array}{l}\text { Alternative } \\
\text { subcohort }\end{array}$} \\
\hline & $n / N$ & $\%$ & $n / N$ & $\%$ \\
\hline \multicolumn{5}{|l|}{ Parental history of atopic manifestations } \\
\hline One or both & $1046 / 2003$ & 52.2 & $237 / 466$ & 50.9 \\
\hline \multicolumn{5}{|l|}{ Sibling history of atopic manifestations } \\
\hline$\geqslant 1$ sibling(s), at least one with atopy & $295 / 2003$ & 14.7 & $93 / 466$ & 20.0 \\
\hline$\geqslant 1$ sibling(s), all without atopy & $773 / 2003$ & 38.6 & $211 / 466$ & 45.3 \\
\hline No siblings & $935 / 2003$ & 46.7 & $162 / 466$ & 34.7 \\
\hline \multicolumn{5}{|l|}{ Vaccination scheme } \\
\hline Standard & $1617 / 1998$ & 80.9 & $198 / 465$ & 42.6 \\
\hline Alternative* & $345 / 1998$ & 17.3 & $118 / 465$ & 25.4 \\
\hline No vaccinations & $36 / 1998$ & 1.8 & $149 / 465$ & 32.0 \\
\hline \multicolumn{5}{|l|}{ Antibiotics ever used } \\
\hline Yes & $452 / 1977$ & 22.9 & $61 / 457$ & 13.3 \\
\hline \multicolumn{5}{|c|}{ Exposure to household ETS $S^{\dagger}>$ than $1 \mathrm{~h} /$ week } \\
\hline Yes & $246 / 1998$ & 12.3 & $10 / 464$ & 2.2 \\
\hline \multicolumn{5}{|l|}{ Pets in the home at any time } \\
\hline Yes & $914 / 1999$ & 45.7 & $209 / 461$ & 45.3 \\
\hline \multicolumn{5}{|l|}{ Breastfeeding during first 4 months } \\
\hline Exclusive & $414 / 2003$ & 20.7 & $259 / 466$ & 55.6 \\
\hline Non-exclusive ${ }^{\ddagger}$ & $1227 / 2003$ & 61.3 & $196 / 466$ & 42.1 \\
\hline Never & $362 / 2003$ & 18.1 & $11 / 466$ & 2.4 \\
\hline \multicolumn{5}{|l|}{ Organic fruit fresh (banana) $)^{\S}$} \\
\hline Yes & $72 / 1330$ & 5.4 & $203 / 360$ & 56.4 \\
\hline \multicolumn{5}{|l|}{ Organic fruit (jar) } \\
\hline Yes & $118 / 1451$ & 8.1 & $174 / 271$ & 64.2 \\
\hline
\end{tabular}

*Delayed or alternative composition of vaccinations.

${ }^{\dagger}$ Environmental tobacco smoke.

${ }^{\ddagger}$ Breastfeeding with supplemental liquids or solid foods.

$\S_{N}=1330$ (conventional subcohort) and $N=360$ (alternative subcohort) due to unknown origin or no consumption of the foods.

${ }^{\top} N=1451$ (conventional subcohort) and $N=271$ (alternative subcohort) due to unknown origin or no consumption of the foods.

the alternative subcohort (2.2\%) and more frequent in the conventional subcohort (12.3\%). Almost half of the families in both subcohorts had pets. The percentage of infants being exclusively breastfed during the first 4 months was 55.6\% in the alternative and $20.7 \%$ in the conventional subcohort. Percentage of organic origin of foods consumed by infants was for banana's 56.4\% in the alternative and $5.4 \%$ of the conventional subcohort, and for fruit from jars $64.2 \%$ in the alternative and $8.1 \%$ in the conventional subcohort.

Overall, the differences in lifestyle characteristics between families with and without parental atopic manifestations were small in both subcohorts (Table 2). In the conventional subcohort, infants were less often exposed to ETS when parents were atopic than when they were non-atopic ( $10.0 \%$ vs. $14.7 \%, P=0.001)$. In the alternative subcohort, exposure to smoking was very low in both 
Table 2. Relation between lifestyle and parental history of atopy in the conventional and alternative lifestyle subcohorts of the KOALA Birth Cohort Study over the first 6 months after birth

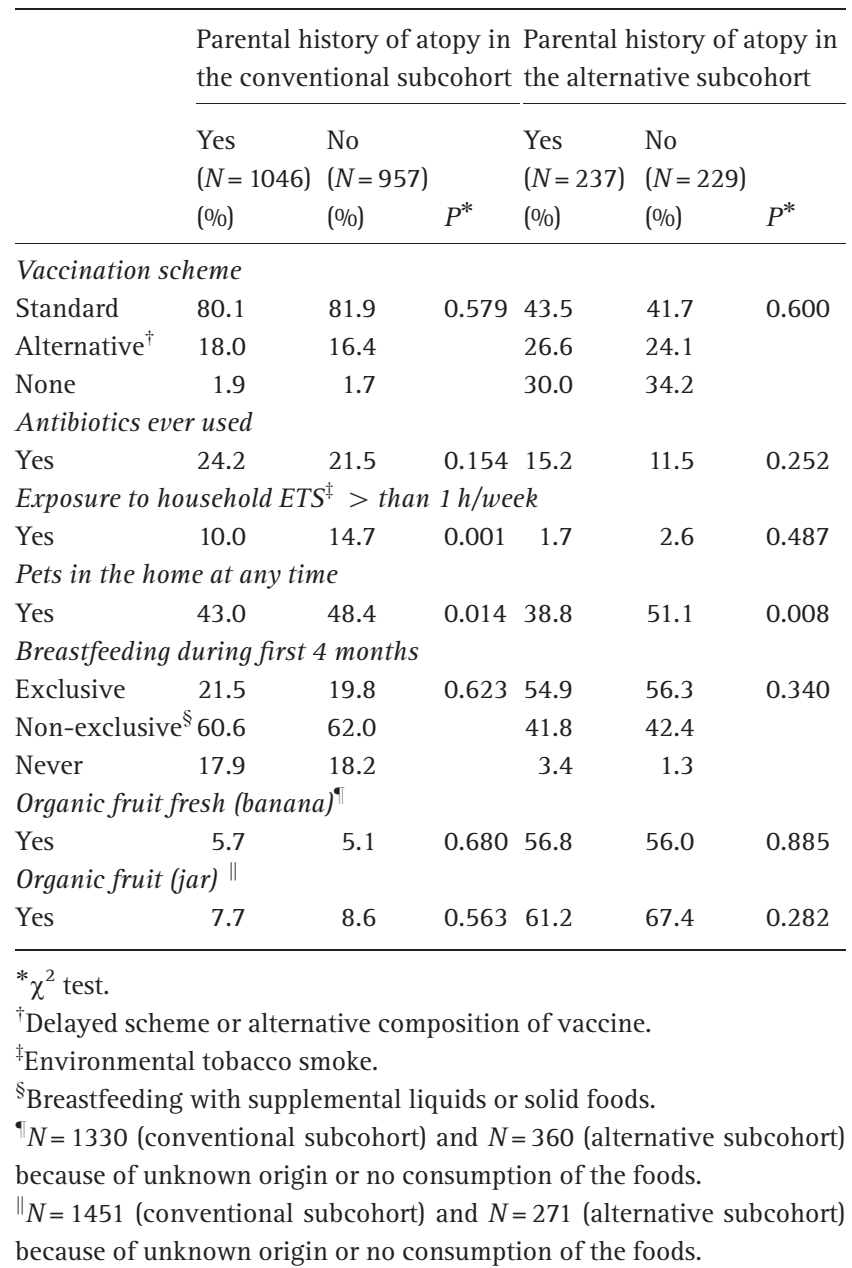

groups (1.7\% vs. $2.6 \%)$. Pets were less often present in families with than without parental atopy $(38.8 \%$ vs. $51.1 \%, P=0.008$ for the alternative subcohort; $43.0 \%$ vs. $48.4 \%, P=0.014$ for the conventional subcohort). Vaccinations scheme, antibiotic use, breastfeeding and consumption of organic fruit did not differ between parents with and without atopic manifestations in both subcohorts.

Differences in lifestyle characteristics between families with atopic manifestations in siblings in both subcohorts were also small (Table 3). Infants with atopic siblings had less often been vaccinated according to the standard scheme than infants with non-atopic siblings in the conventional subcohort ( $72.4 \%$ vs. $81.8 \%, P<0.001)$. In the alternative subcohort, the difference was in the same direction but not statistically significant $(29.0 \%$ vs. $39.5 \%, P=0.164)$. Antibiotic use, exposure to ETS, pets and breastfeeding and consumption of organic foods (except for consuming bananas of organic origin in the alternative subcohort) did not differ between families with
Table 3. Relation between lifestyle and sibling history of atopy in families with older siblings in the conventional and alternative lifestyle subcohorts of the KOALA Birth Cohort Study over the first 6 months after birth

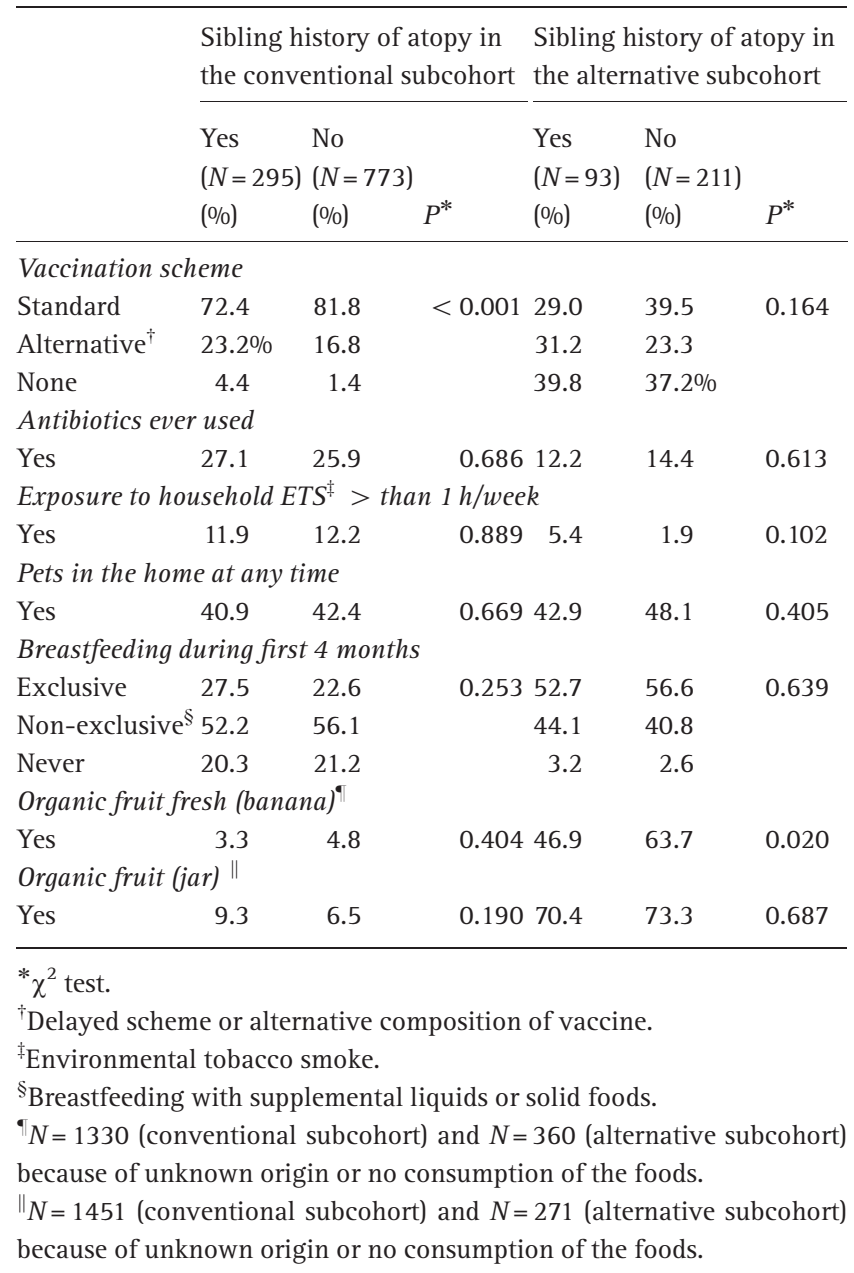

and without a history of atopic manifestations in siblings in both subcohorts.

We found similar results when we restricted our definition of atopic manifestations to a (self-reported) doctor's diagnosis of asthma, pet or HDM allergy, hayfever, or eczema separately. Differences in lifestyle characteristics between atopic and non-atopic families were of the same size and were only found for less smoking (when parents had a history of pet or HDM allergy or hayfever), fewer pets (when parents had a history of pet or HDM allergy or eczema) and lower frequencies of standard vaccination schemes (when siblings had a history of asthma or eczema) but not for antibiotic use, breastfeeding and consumption of organic foods.

We further evaluated maternal smoking or exposure to ETS during pregnancy, having pets during pregnancy, as well as parents' intention to have their infant vaccinated according to the standard scheme (asked during pregnancy). In the conventional subcohort, atopic pregnant 
women smoked less or were less often exposed to ETS than non-atopic pregnant women, but the difference was not statistically significant ( $8.0 \%$ vs. $10.1 \%, P=0.101)$. In the alternative subcohort, maternal smoking or exposure to environmental tobacco smoking was very low in both groups $(0.0 \%$ vs. $1.1 \%)$. In the conventional subcohort, during pregnancy, atopic parents had pets less often than non-atopic parents $(49.7 \%$ vs. $54.5 \%, P=0.021)$. In the alternative subcohort, the difference was in the same direction ( $42.2 \%$ vs. $50.2 \%, P=0.082$ ). In the conventional subcohort, during pregnancy, parents of atopic siblings less often indented their child-to-come to be vaccinated according to the standard scheme than parents of nonatopic siblings ( $91.2 \%$ vs. $96.2 \%, P=0.001)$. In the alternative subcohort, the difference was in the same direction but not statistically significant $(53.0 \%$ vs. $60.2 \%$, $P=0.143$ ). Finally, results from multiple logistic regression analyses showed that parental and sibling's history were independently associated with the lifestyle practices mentioned above (smoking, pets, and vaccination scheme) and these associations were not statistically different between the conventional and alternative subcohorts (test-of-interaction; results not shown).

\section{Discussion}

Some 'prudent' lifestyle characteristics differed between atopic and non-atopic families, depending on whether atopic manifestations were present in parents or older siblings. A home environment with fewer pets and less exposure to environmental tobacco smoke (ETS) was related to a parental but not to a sibling history of atopic manifestations. Newborns were less often vaccinated according to the standard scheme when siblings but not parents had a history of atopic manifestations. These findings were observed in our study with a relatively large group of families with alternative lifestyles. Because of the small intervals between the follow-up questionnaires, recall bias was kept to a minimum. This is particularly important as parents with alternative lifestyle choices may recall health-related lifestyle choices more accurately than a general population sample.

One may argue that a definition of atopic manifestations including asthma, pet or HDM allergy, hayfever as well as eczema has a low specificity. We therefore evaluated differences in lifestyle characteristics for these atopic manifestations separately. Differences in lifestyle characteristics between atopic and non-atopic families were of the same size and were only found for the same lifestyle characteristics (pets, exposure to ETS and vaccinations), which might indicate that our definition of atopy was specific enough to evaluate our research question.

Several points merit consideration. First, parents who have 'prudent' lifestyle characteristics may also have a different way of labelling atopic complaints. Second, differences in reporting atopic symptoms may have occurred between the conventional and alternative subcohorts owing to diagnostic differences. Therefore, a direct comparison of prevalence rates between both subcohorts has to be made with caution, which was why we have presented our results for these two subcohorts separately. Finally, the differences in lifestyle practices between atopic and non-atopic families in our study were small and cannot have a strong confounding effect, suggesting that confounding by indication will presumably be limited in our study. This may be different in other birth cohort studies because of differences in study population characteristics and study design. Like every other study, our study deals with self-selection of participants [25]. In this population with a probably high interest in health, one could have expected substantial differences between atopic and non-atopic families with regard to 'prudent' lifestyle choices. However, we report only small differences and expect differences to be even smaller in a general population.

An earlier Dutch study on differences in lifestyle and between allergic and non-allergic parents among 3147 infants aged 2-3 months revealed, like our study, a relationship between lifestyle factors related to pets or smoking and allergic disease in parents [27]. Infants of allergic parents were more likely than other infants to be born in a home free of cats and cigarette smoking. The infants of allergic parents in this study were later exposed to newly introduced foods. In our study, however, we did not find differences between families with and without a parental history of atopic manifestations with regard to exclusive breastfeeding for at least 4 months, which can be regarded as an indicator for postponing the introduction of artificial and/or supplemental feeding in this period. The study did not address the issue of atopy in siblings. There are few examples of studies that look into the separate effect of parental and sibling atopic manifestations.

Fewer pets and less exposure to ETS were significantly related to parental but not to sibling history of atopic manifestations. A potential explanation is the notion that atopic parents may experience effects of smoking or pets on their own health, and therefore take precautions as they anticipate the susceptibility of their child. In case of sibling but not parental atopic manifestations, there was a significant positive relation with alternative vaccination schemes. It is possible that either side effects of vaccinations or atopic disease in older siblings made parents decide to alter their vaccination policy for their present child. These observations suggest a self-inflicted prudent lifestyle adopted by parents with a family history of atopic manifestations in order to protect their child against atopic disease development (confounding by indication).

We considered 'reverse causation' as a possible explanation for our findings. Reverse causation in our study would mean that atopy in the index child had changed the 
lifestyle of the parents. We evaluated associations between a parental history of atopy and having pets and exposure to ETS as measured before the index child was born (during pregnancy). We did the same for a sibling's history of atopy and intention to have the index child vaccinated according to the standard scheme. Less exposure to ETS might have been influenced by atopy in the index child, as the difference between atopic and non-atopic mothers that smoked or were exposed to ETS during pregnancy was not statistically significant.

In summary, some 'prudent' lifestyle characteristics differed between atopic and non-atopic families, depending on whether atopic manifestations were present in parents or older siblings. This has important consequences for the validity in epidemiological studies on the aetiology of allergy in children. Confounding by indication because of a family history of atopic manifestations can best be controlled for by considering atopy in parents and siblings as separate confounders.

\section{Acknowledgements}

We thank Dr Edmond Schoorel for giving valuable advice, and also all parents and infants who participated in this study.

\section{References}

1 von Mutius E. The rising trends in asthma and allergic disease. Clin Exp Allergy 1998; 5:45-9.

2 Sears MR. Epidemiology of childhood asthma. Lancet 1997; 350:1015-20.

3 Worldwide variation in prevalence of symptoms of asthma, allergic rhinoconjunctivitis, and atopic eczema: ISAAC Steering Committee. Lancet 1998; 351:1225-32.

4 Duffy DL. Genetic epidemiology of asthma. Epidemiol Rev 1997; 19:129-43.

5 von Mutius E, Fritzsch C, Weiland SK, Roll G, Magnussen H. Prevalence of asthma and allergic disorders among children in united Germany: a descriptive comparison. BMJ 1992; 305: 1395-9.

6 von Mutius E, Martinez FD, Fritzsch C, Nicolai T, Roell G, Thiemann HH. Prevalence of asthma and atopy in two areas of West and East Germany. Am J Respir Crit Care Med 1994; 149: 358-64.

7 Cookson W. The alliance of genes and environment in asthma and allergy. Nature 1999; 402:B5-11.

8 Alm JS, Swartz J, Lilja G, Scheynius A, Pershagen G. Atopy in children of families with an anthroposophic lifestyle. Lancet 1999; 353:1485-8.

9 Von Ehrenstein OS, Von Mutius E, Illi S, Baumann L, Bohm 0, von Kries R. Reduced risk of hay fever and asthma among children of farmers. Clin Exp Allergy 2000; 30:187-93.
10 Braun Fahrlander C, Gassner M, Grize L et al. Prevalence of hay fever and allergic sensitization in farmer's children and their peers living in the same rural community. Clin Exp Allergy 1999; 29:28-34.

11 Riedler J, Braun Fahrlander C, Eder W et al. Exposure to farming in early life and development of asthma and allergy: a crosssectional survey. Lancet 2001; 358:1129-33.

12 Wickens KL, Crane J, Kemp TJ et al. Family size, infections, and asthma prevalence in New Zealand children. Epidemiology 1999; 10:699-705.

13 Bodner C, Godden D, Seaton A. Family size, childhood infections and atopic diseases. Thorax 1998; 53:28-32.

14 Jarvis D, Chinn S, Luczynska C, Burney P. The association of family size with atopy and atopic disease. Clin Exp Allergy 1997; 27:240-5.

15 Steerenberg PA, Van Amsterdam JG, Vandebriel RJ, Vos JG, Van Bree L, Van Loveren H. Environmental and lifestyle factors may act in concert to increase the prevalence of respiratory allergy including asthma. Clin Exp Allergy 1999; 29:1303-8.

16 Ceuppens J. Western lifestyle, local defenses and the rising incidence of allergic rhinitis. Acta Otorhinolaryngol Belg 2000; 54:391-5.

17 Wickens K, Pearce N, Crane J, Beasley R. Antibiotic use in early childhood and the development of asthma. Clin Exp Allergy 1999; 29:766-71.

18 Seaton A, Godden DJ, Brown K. Increase in asthma: a more toxic environment or a more susceptible population? Thorax 1994; 49:171-4.

19 Black PN, Sharpe S. Dietary fat and asthma: is there a connection? Eur Respir J 1997; 10:6-12.

20 Lau S, Illi S, Sommerfeld C et al. Early exposure to house-dust mite and cat allergens and development of childhood asthma: a cohort study. Lancet 2000; 356:1392-7.

21 Custovic A, Simpson BM, Simpson A et al. Current mite, cat, and dog allergen exposure, pet ownership, and sensitization to inhalant allergens in adults. J Allergy Clin Immunol 2003; 111: 402-7.

22 Wahn U, Lau S, Bergmann R et al. Indoor allergen exposure is a risk factor for sensitization during the first three years of life. J Allergy Clin Immunol 1997; 99:763-9.

23 Sporik R, Holgate ST, Platts Mills TA, Cogswell JJ. Exposure to house-dust mite allergen (Der p I) and the development of asthma in childhood. A prospective study. N Engl J Med 1990; 323:502-7.

24 Schayck CP, Knottnerus JA. Can the 'hygiene hypothesis' be explained by confounding by behaviour? J Clin Epidemiol 2004; 57:435-7.

25 Kummeling I, Thijs C, Penders J et al. Etiology of atopy in infancy: the KOALA Birth Cohort Study. Pediatr Allergy Immunol 2005; 16:679-84.

26 Bastiaanssen JM, de Bie RA, Bastiaenen CH et al. Etiology and prognosis of pregnancy-related pelvic girdle pain; design of a longitudinal study. BMC public health 2005; 5:1-8.

27 Wijga A, Smit HA, Brunekreef B et al. Are children at high familial risk of developing allergy born into a low risk environment? The PIAMA Birth Cohort Study. Clin Exp Allergy 2001; 31:576-81. 